
April 1939

\title{
INTERNATIONAL TEMPERATURE SCALE AND SOME RELATED PHYSICAL CONSTANTS
}

\author{
By H. T. Wensel
}

\section{ABSTRACT}

The situation in regard to the radiation constants is reviewed primarily for the purpose of selecting the value of $c_{2}$ to use in Planck's equation for securing, above $1063^{\circ} \mathrm{C}$, a temperature scale which most nearly conforms with the thermodynamic scale. The values in the literature are discussed, and some data are presented for deriving $c_{2}$ from gas thermometry data. The constants arrived at are the following:

$$
\begin{aligned}
\sigma & =(5.70 \pm 0.02) \times 10^{-5} \mathrm{erg} \mathrm{sec}-1 \mathrm{~cm}^{-2} \mathrm{deg}-4 \\
c_{1} & =(3.732 \pm 0.006) \times 10^{-5} \mathrm{erg} \mathrm{cm}^{2} \mathrm{sec}^{-1} \\
c_{2} & =1.436 \pm 0.001 \mathrm{~cm} \mathrm{deg} \\
\lambda_{m} T & =(2892 \pm 2) \times 10^{-4} \mathrm{~cm} \mathrm{deg} \\
M & =\text { least mechanical equivalent of light }=0.00151 \pm 0.00001 \text { watt ("new" } \\
& \text { lumen) })^{-1}
\end{aligned}
$$

\section{CONTENTS}

I. International Temperature Scale

II. The radiation constants _._.

III. Auxiliary constants:

1. Velocity of light _._. 379

2. Kelvin temperature of the ice point and the value of $R \ldots \ldots 379$

3. International Electrical Units_... 379

4. The faraday $\ldots \ldots \ldots$

5. Values of $e$ and $h \ldots 382$

IV. Values of $c_{2}$ from $\lambda_{m} T \ldots$

V. Values of $c_{2}$ from $\sigma_{\ldots} \ldots \ldots 33$

VI. Values of $c_{2}$ based on optical-pyrometer measurements

VII. Values of $c_{2}$ from atomic constants

VIII. Summary

IX. References $\ldots \ldots$

\section{INTERNATIONAL TEMPERATURE SCALE}

In 1927 the Seventh General Conference of Weights and Measures, representing 31 nations, unanimously adopted the International Temperature Scale [1]. ${ }^{.}$If the ratio of any two temperatures be defined by the equation $T_{2} / T_{1}=1-E$, where $E$ is the efficiency of a completely reversible heat engine operating between a source at temperature $T_{1}$ and a sink at temperature $T_{2}$, and if further the temperature interval between the steam point and the ice point be defined as $100^{\circ}$, the resultant scale is the thermodynamic scale advocated by Lord Kelvin. Temperatures on this scale, known as the Kelvin Scale, are designated as " $\mathrm{K}$ " and denoted by the symbol $T$. The lower limit of temperature is $0^{\circ} \mathrm{K}$, and the normal freezing point of water, called the ice point and designated by the symbol $T_{0}$, is fourd by experiment to be approximately $273^{\circ} \mathrm{K}$.

\footnotetext{
${ }_{1}$ Numbers in brackets indicate the literature references at the end of this paper.
} 
The Kelvin Scale and other scales on which numerical values of temperature are a linear function of $T$ are the only thermodynamic scales which have been used to any considerable extent. If we write $t=T-T_{0}, t$ is the temperature on a scale which is called the Thermodynamic Centigrade Scale. Any temperature interval has the same numerical value when expressed on this scale as when expressed on the Kelvin Scale. The International Temperature Scale "conforms with the thermodynamic [centigrade] scale as closely as is possible with present knowledge" and "is to be regarded as susceptible of revision and amendment as improved and more accurate methods of measurement are evolved."

The possibility of revising the scale to secure some improvement appeared soon after the scale was adopted. Below $660^{\circ} \mathrm{C}$ the scale is defined by the standard resistance thermometer and from $660^{\circ} \mathrm{C}$ to the gold point, defined as $1063.0^{\circ} \mathrm{C}$, the scale is defined by the standard thermocouple. The standard thermocouple and the standard resistance thermometer are made to agree at the freezing point of antimony, $630.5^{\circ} \mathrm{C}$, but agreement at $660^{\circ} \mathrm{C}$ was left to chance. In 1929 Roeser [2] found that the agreement was within $0.01^{\circ} \mathrm{C}$ at the melting point of the sample of aluminum, $659.23^{\circ} \mathrm{C}$, at which he compared thermocouples and resistance thermometers. Roeser used two thermocouples and obtained agreement to $0.01^{\circ} \mathrm{C}$ with one and $0.00^{\circ}$ $\mathrm{C}$ with the other. It subsequently developed [3], however, that the silver used in this work had a freezing point $0.48^{\circ} \mathrm{C}$ lower than that of pure silver, corresponding to a difference of 5.5 microvolts in the electromotive force yielded by Roeser's thermocouples at the silver point. Making this correction, it is found that these thermocouples indicate the freezing point of the aluminum used to be $659.05^{\circ} \mathrm{C}$, whereas the standard resistance thermometer indicated the temperature to be $659.23^{\circ} \mathrm{C}$. Inasmuch as the standard thermocouple defines the scale only from $660^{\circ}$ to $1063^{\circ} \mathrm{C}$, the temperature in question is $659.23^{\circ} \mathrm{C}$ (Int. 1927), because it is in the range of the scale defined by the standard thermometer. Subsequently, the freezing point of a lot of aluminum to be used for standard samples was measured ${ }^{2}$ with a standard resistance thermometer as $660.01^{\circ} \mathrm{C}$ and with a standard thermocouple as $695.87^{\circ} \mathrm{C}$. The temperature in question is above the range defined in terms of the resistance thermometer and below the range defined in terms of the thermocouple and therefore cannot be expressed on the International Temperature Scale of 1927. This situation can be remedied by limiting the range of the scale defined by the resistance thermometer to temperatures below the freezing point of antimony and extending the range of the thermocouple down to that point.

Above the melting point of gold, the scale might well be based on the Planck formula instead of the Wien formula, which was used in defining the 1927 scale [1] up to about $5000^{\circ} \mathrm{C}$, where $\lambda(t+273)$ is less than $0.3 \mathrm{~cm}$ deg. The use of the Planck formula would make no significant change in the scale below $5000^{\circ} \mathrm{C}$ and would result in a scale which conforms closely to the thermodynamic scale at all temperatures above the gold point.

A study of the question of whether other revisions might secure still closer conformity has led, among other things, to a re-evaluation of the

\footnotetext{
2 The resistance thermometer measurements were made by R.S. Jessup and the thermocouple measure ments by A. I. Dahl.
} 
radiation constant which is used in defining the scale at high temperatures. A true perspective of the data on the radiation constants cannot be obtained without consideration of a number of other physical constants more or less directly related to the radiation constants. The numerical values of some of these related constants have been established so accurately that, in combining them with other constants which are much less accurately established, they may be treated as exact. Nevertheless, it seemed worth while to discuss all the constants involved in some detail, either to indicate how little the value selected contributes to the uncertainty of the derived radiation constants or to make the incidental results of this study available to readers who may find them of interest.

\section{THE RADIATION CONSTANTS}

The constants by means of which the energy radiated by a black body may be characterized are $c_{1}, c_{2}, \sigma, \lambda_{m} T$, and $\nu_{m} / T$ defined by the formulas

$$
\begin{gathered}
J_{\lambda}=c_{1} \lambda^{-5}\left(e^{\frac{c_{2}}{\lambda T}}-1\right)^{-1} \\
J_{\nu}=c_{1} c^{-4} \nu^{3}\left(e^{\frac{c_{2} \nu}{T}}-1\right)^{-1} \\
\int_{0}^{\infty} J_{\lambda} d \lambda=\int_{0}^{\infty} J_{\nu} d \nu=\sigma T^{4} \\
\lambda_{m} T=\frac{c_{2}}{A}=0.201405 c_{2},
\end{gathered}
$$

where

and

where

$$
A=5\left(1-e^{-A}\right)
$$

In the above formulas

$\lambda$ is the wavelength

$\nu$ is the frequency

$c(=\lambda \nu)$ is the velocity of light

$T$ is temperature in degrees $\mathrm{K}$

$e$ is the Naperian base, $2.7182818 \ldots$

$J_{\lambda}$ is the radiant energy (of wavelength $\lambda$ ) per unit wavelength interval emitted per unit time by unit area of a black body throughout the solid angle $2 \pi$, i. e., "hemispherical radiation."

$J_{\nu}$ is the radiant energy (of frequency $\nu$ ) per unit frequency interval emitted per unit time by unit area of a black body throughout the solid angle $2 \pi$.

$\lambda_{m}$ and $\nu_{m}$ are the values of $\lambda$ and $\nu$ at which $J_{\lambda}$ and $J_{\nu}$, respectively, are a maximum for any given value of $T$.

It should be pointed out that, for a given value of $T, \lambda_{m}$ and $\nu_{m}$ do not correspond to the same region of the spectrum. In other words, 
their product is not $c$ but $c(B / A)$, or $0.56825 c$, so that $\nu_{m}$ is displaced toward the red end of the spectrum from the value of $\nu$ corresponding to $\lambda_{m}$. This may be seen by writing $d \nu=-\left(c / \lambda^{2}\right) d \lambda$.

All magnitudes will be expressed in cgs units, i. e., $\lambda$ in $\mathrm{cm}, J_{\lambda}$ in erg $\mathrm{sec}^{-1} \mathrm{~cm}^{-3}, c_{1}$ in erg $\mathrm{sec}^{-1} \mathrm{~cm}^{2}, c_{2}$ in $\mathrm{cm} \mathrm{deg}, \sigma$ in erg $\mathrm{sec}^{-1} \mathrm{~cm}^{-2} \mathrm{deg}^{-4}$, etc. In giving numerical values, factors of $10^{n}$ and the cumbersome designation of units such as those above will often be omitted after the first writing when it is felt that no ambiguity will result.

We have the following relations

$$
\begin{aligned}
& c_{1}=2 \pi c^{2} h=\frac{15}{\pi^{4}} \sigma c_{2}^{4}, \\
& c_{2}=\frac{c h}{k}=\left(\frac{h}{e}\right) \frac{c F}{R}, \text { and } \\
& \sigma=\frac{2 \pi^{5} c^{2} h}{15 c_{2}^{4}}=40.8026 \frac{c^{2} h}{c_{2}^{4}},
\end{aligned}
$$

where $c=$ the velocity of light in $\mathrm{cm} \mathrm{sec}^{-1}$

$h=$ Planck's constant of action in erg sec

$k=$ the Boltzmann constant in erg deg $^{-1}$

$e=$ electronic charge in electrostatic units (esu).

$F=$ the faraday constant in (esu) $\mathrm{mole}^{-1}$

$R=$ the gas constant in erg $\mathrm{deg}^{-1} \mathrm{~mole}^{-1}$.

There are a number of reviews available on the best values of the physical constants derivable from experimental data, but the radiation constants have not received much attention in recent years. The experimental values of $\sigma$ and $c_{2}$ have usually been used to calculate values of $h$, but not much weight has been given to the results. Better values of the radiation constants can be derived from atomic constants than from the published experimental values, and it seems worth while to make a critical study of these related constants for the primary purpose of deducing the most probable value of the constants which appear in the formulas for black-body radiation.

For practical work, a knowledge of the numerical value of any radiation constant, excepting $c_{2}$, to better than 1 or 2 percent is seldom required. Measurements involving $J_{\lambda}$ are usually so made as to depend only on ratios in which $c_{1}$ cancels out. Even when this is not the case, an accurate value of $c_{1}$ is seldom of interest, because we have at present no technique for accurate measurements of $J_{\lambda}$. The situation in regard to $\sigma$ is substantially the same. The only experiments in which anything besides an approximate value of $\sigma$ is of interest are those made for the purpose of determining $\sigma$.

Our interest in the constant $c_{2}$ lies in the fact that it is one of the constants used in defining the International Temperature Scale above the melting point of gold. This definition is "by means of the formula

$$
\log _{e} \frac{J_{2}}{J_{1}}=\frac{c_{2}}{\lambda}\left(\frac{1}{1336}-\frac{1}{(t+273)}\right)
$$

The constant $c_{2}$ is taken as $1.432 \mathrm{~cm}$ degrees. The equation is valid if $\lambda(t+273)$ is less than $0.3 \mathrm{~cm}$ degrees." In this equation $J_{1}$ and $J_{2}$ are the values of $J_{\lambda}$ at the melting point of gold, defined as $1063^{\circ}$, and at the temperature $t$, respectively. A change in $c_{2}$ of 1 percent results 
in a change in $t$ of more than $10^{\circ}$ at the melting point of platinum and of more than $60^{\circ}$ at the melting point of tungsten.

\section{AUXILIARY CONSTANTS}

In giving the numerical value of a quantity it is usually advisable to add a numerical statement of the uncertainty associated with the value given. The \pm terms in this paper represent the limits within which it is estimated that the true value is included with a probability of about 0.9 . They represent merely the author's opinion and may bear little relation to the mean deviation.

\section{VELOCITY OF LIGHT}

The velocity of light is so accurately known that, for the calculations made in this paper, it may be treated as exact. Karolus and Mittlestaedt [4] obtained the value $2.99778 \times 10^{10}$, while (Michelson), Pease, and Pearson [5] obtained the value $2.99774 \times 10^{10}$. The velocity of light is taken as

$$
c=(2.99776 \pm 0.00020) \times 10^{10} \mathrm{~cm} \mathrm{sec}^{-1} .
$$

\section{KELVIN TEMPERATURE OF THE ICE POINT AND THE VALUE OF $R$}

The temperature of the ice point on the Kelvin Scale, $T_{0}$, has been derived in a number of laboratories. The most recent and reliable of the values are listed in table 1.

TABLE 1.-Recent values of $\mathrm{T}_{0}$

\begin{tabular}{|c|c|c|c|}
\hline Authors & Laboratory & Date & $T_{0}$ \\
\hline $\begin{array}{l}\text { Heuse and Otto [6] } \\
\text { Keesom and Tuyn [7] } \\
\text { Roebuck [8] } \\
\text { Kinoshita and Oishi }[9] \\
\text { Beattie [10] }\end{array}$ & $\begin{array}{l}\text { PTR } \\
\text { Leiden } \\
\text { University of Wisconsin } \\
\text { Tokyo University } \\
\text { MIT }\end{array}$ & $\begin{array}{l}1930 \\
1936 \\
1936 \\
1937 \\
1937-\ldots-1\end{array}$ & $\begin{array}{r}273.16 \\
273.14_{4} \\
273.16 \\
273.167 \\
273.16-273.17 \\
\end{array}$ \\
\hline & & Mean. & 273.16 \\
\hline
\end{tabular}

The value 273.16 to 273.17 listed for Beattie is provisional as Beattie's final calculations have not been completed. On the basis of the determinations listed in table 1,

$$
T_{0}=273.16 \pm 0.02^{\circ} \mathrm{K} \text {. }
$$

The value of $R T_{0}$ needs little comment as it is known more accurately than $T_{0}$. The value for $R T_{0}$ given by Birge [11] reduces to $2.2711 \times 10^{10} \mathrm{erg} \mathrm{mole}^{-1}$. Combining this with $T_{0}=273.16$, the value of $R$ is found to be

$$
R=(8.3142 \pm 0.0010) \times 10^{7} \mathrm{erg} \mathrm{deg}^{-1} \mathrm{~mole}^{-1} .
$$

\section{INTERNATIONAL ELECTRICAL UNITS}

Many of the experimental data to be considered are expressed in International Electrical Units. In order to reduce the published 
results to electrostatic units (esu) for substitution in eq 9 the ratios of the international to the absolute units must be used. The most recent published determinations of the ratios of the international to the absolute (practical) units are summarized on page 113 of the Procès Verbaux des Seances, Comité International des Poids et Mesures of 1937. Inasmuch as this publication is not generally available the summary is reproduced below:

\begin{tabular}{|c|c|c|}
\hline $\begin{array}{l}\text { ETL (Japan) } \\
\text { NBS (U. S.) } \\
\text { NPL (Great Britain) } \\
\text { PTR (Germany) }\end{array}$ & $\begin{array}{l}1 \text { international ohm } \\
1 \text { international ohm } \\
1 \text { international ohm } \\
1 \text { international ohm }\end{array}$ & $\begin{array}{l}=1.00046_{5} \text { abs. ohms. } \\
=1.00045_{4} \text { abs. ohms. } \\
=1.00050_{4} \text { abs. ohms. } \\
=1.00048_{3} \text { abs. ohms. }\end{array}$ \\
\hline 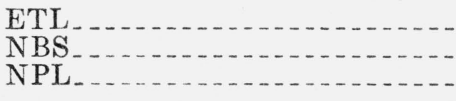 & $\begin{array}{l}1 \text { international am } \\
1 \text { international am } \\
1 \text { international am }\end{array}$ & $\begin{array}{l}=0.99993_{8} \mathrm{ab} \\
=0.99989_{5} \mathrm{ab}\end{array}$ \\
\hline 次次 & $\begin{array}{l}1 \text { international volt } \\
1 \text { international volt } \\
1 \text { international volt }\end{array}$ & $\begin{array}{l}=1.000403 \text { abs. volts. } \\
=1.000349 \text { abs. volts. } \\
=1.000352 \text { abs. volts. }\end{array}$ \\
\hline
\end{tabular}

The most recent NBS value [12] for the ampere, however, is 0.99986 , which is in remarkably good agreement with the NPL value. From these data the following values have been derived:

\section{$\frac{1 \text { International } \mathrm{Ohm}}{1 \text { Absolute Ohm }}=p=1.00048$.}

\section{International Ampere \\ 1 Absolute Ampere $=q=0.99986$.}

\section{International Volt 1 Absolute Volt $=p q=1.00034$.}

\section{THE FARADAY}

In 1929 Birge [11] recommended 96,487 abs. coul. for the faraday and is still using this value, since his latest value [13] of 96,513.1 abs. coul. per mole on the physical scale (atomic weight of oxygen $=1.00027$ $\times 16)$ is simply 1.00027 times his 1929 value. This value is based entirely on the determinations of $F$ with the silver voltameter. It is the proper value to use in equations connecting atomic constants (as Birge himself points out) only if the measured amount of silver deposited in a silver voltameter by the passage of a given charge of electricity truly represents the mass associated with that amount of charge. There is reason to believe that this is not the case. While it is true that the difference is of no consequence in deriving values of the radiation constants, it cannot be ignored if one wishes to express the faraday to 0.1 coul.

In the first place, on account of inclusions and similar causes, the mass deposited by one coulomb is not the mass of silver ions with which one coulomb of charge is associated. Correction is usually made for inclusions, but there may be other effects which are not known. In the second place, the amount of silver deposited is not necessarily the amount of silver weighed. It may be worth while to quote a few sentences from a discussion of this question by Rosa and Vinal [14]. "The precaution taken by some observers to soak the silver deposits over night in distilled water to remove the last traces 
of electrolyte was shown to be harmful because it was discovered that silver in contact with platinum is appreciably soluble in distilled water. This was shown by repeated tests. The silver and the platinum differ slightly in potential so that a current passes from the silver to the platinum through the water." If acid is present in the electrolyte there will, of course, be a re-solution of the deposit. Although there is no difficulty in avoiding loss of deposit due to acidity of the electrolyte, the question of re-solution in a neutral electrolyte still remains, inasmuch as in the usual form of silver voltameter, the silver is deposited on platinum.

All of these effects, as long as they are constant, have no bearing on the use of the silver voltameter as a device for reproducing the international ampere defined as the current which will deposit $0.001118 \mathrm{~g}$ of silver per second in a silver voltameter. The technique of the silver voltameter has been so well worked out that it is a precision device capable of being used to check the voltage of the Weston normal cell. Rosa and Vinal [14] list six determinations of this voltage in five different countries with an average deviation of 1 part in $10^{5}$ from the mean and a maximum deviation of less than 2 parts in $10^{5}$.

The international ampere, so defined, is thus transferred to standard cells and material resistance standards (wire coils) which are then used to reproduce the international ampere in the various national laboratories. There are small differences in these material standards but they amount to only a few parts in $10^{5}$ and can be neglected. We have then, from the silver experiments, that

$$
F=\frac{\text { at. wt. of } \mathrm{Ag}}{0.001118}=\frac{107.880}{0.001118}=96,494 \text { int. coul. mole }{ }^{-1} .
$$

While the statement "in a silver voltameter a weighed deposit of 1 mole will result from the passage of 96494 int. coul." is true to about 1 part in $10^{5}$, the uncertainty in the above figure as a value of $F$ is determined by the magnitude of the effects described earlier. We will not question the fact, which must be true if values of the specific electronic charge, $e / m$, are to be deduced from $F$, that each univalent ion carries the charge $e$.

It is evident, then, that the definition of the international ampere in terms of the silver voltameter does not confer any special virtue on silver in the determination of the faraday. In fact, if we used a different element which was free from all effects of the kind described, it would yield a more reliable value of $F$. Unfortunately, there are very few elements that are suitable. There must be no question of the valence. If we have, for example, both univalent and divalent ions, the result will be entirely useless. Iodine is one of the few that can be used. It is free from the effect of inclusions, but the mass determined by titration may differ from the mass deposited due to oxidation by the arsenious acid solution used in the titration. The value of the faraday obtained with the iodine voltameter is 96,514 int. coul. per g equiv. [15]. There seems no logic, whatever, in ignoring the iodine value. The effects in the two cases are not known, but it seems fairly certain that the faraday lies somewhere between the two values whose mean is 96,504 int. coul. There is no point in weighting the silver value higher than the other simply because more work has been done with the silver voltameter. This difference of 20 parts 
per $10^{8}$ is inherent in the two methods and would probably not be greatly changed by more determinations.

To get $F$ in units which can be used by atomic physicists we must know the relation between the absolute and international ampere. For this we now have a reliable conversion factor $q$. The various determinations yield the ratio of the size of the absolute ampere to the international ampere as represented in each case by the material standards, standard cells and standard resistance coils, at the national laboratory making the determination. The differences in these material standards can be neglected and well within the accuracy with which we can at present evaluate the faraday, the conversion factors apply to the international ampere as defined in terms of the silver voltameter, that is, to the value of $F=96,504$.

In 1906-07 an extended investigation was carried out at the National Physical Laboratory [16] in which the silver deposited by one absolute coulomb in the "New Form" of silver voltameter was $0.00111815_{1}$. The absolute ampere was realized with the Ayrton-Jones current balance. This is not a determination of $F$, but a determination of

$$
q=\frac{0.0011180}{0.00111815_{1}}=0.99986 \text {. }
$$

This value, while not comparable in accuracy with recent determinations, agrees surprisingly well with the best of these.

The value of the faraday is then 96,504 int. coul. mole ${ }^{-1}$, or 96,490 abs. coul. mole ${ }^{-1}$. This value does not differ much from the one Birge is now using but is based on different data. His use of only the silver data was to a large extent balanced by his use of an obsolete value of $q$ :

Expressing the result in electrostatic units

$$
F=(2.8926 \pm 0.0002) \times 10^{14}(\mathrm{esu}) \mathrm{mole}^{-1}
$$

\section{VALUES OF $e$ AND $h$}

For the purposes of this paper an accurate value of the ratio $h / e$ is of far more concern than accurate values of either $h$ or $e$. There is some divergence in the fourth significant figure of the value advocated for $e$. It appears that the value derived by Von Friesen [17] is based upon impartial consideration of the data available. This value is

$$
e=(4.800 \pm 0.005) \times 10^{-10}(\mathrm{esu})
$$

The value of $e=4.800$ and the value of $h / e$ listed on page 392 lead to a value of

$$
\boldsymbol{h}=(6.61 \pm 0.01) \times 10^{-27} \mathrm{erg} \mathrm{sec} .
$$

This value agrees to three significant figures with all the recent values, see table 5 .

\section{VALUES OF $c_{2}$ FROM $\lambda_{m} T$.}

One of the most direct methods of evaluating $c_{2}$ is by the use of eq 4. The published results are listed in table 2. 
TABLE 2.-Values of $c_{2}$ from measurements of $\lambda_{m} T$

\begin{tabular}{|c|c|c|c|}
\hline Authors & Year & Published values & $\begin{array}{l}\text { Selected } \\
\text { values }\end{array}$ \\
\hline Lummer and Pringsheim [18] & $\left\{\begin{array}{l}1899 \\
1901\end{array}\right.$ & $\begin{array}{l}1.43 \text { and } 1.46 \ldots \ldots \\
1.458\end{array}$ & 1.45 \\
\hline Paschen and Wanner [19] ..... & $\left\{\begin{array}{l}1899 \\
1900 \\
1901\end{array}\right.$ & $1.435-141$ & 1.44 \\
\hline Holborn and Valentiner [20].... & $\left\{\begin{array}{l}1907 \\
1912\end{array}\right.$ & $1.42 \ldots$ & 1.435 \\
\hline Warburg, Leithauser, Hupka, and Müller [21] ... & $\left\{\begin{array}{l}1910 \\
1911 \\
1912 \\
1913 \\
1915\end{array}\right.$ & $\begin{array}{l}1.457 \\
1.42 \text { to } 1.46 \\
1.436 \text { and } 1.438 \\
1.4374 \\
1.425 \text { and } 1.43 \text { to } 1.44\end{array}$ & 1.43 \\
\hline Coblentz [22]_-. & $\left\{\begin{array}{l}1914 \\
1916 \\
1922\end{array}\right.$ & 1.4465 & 1.432 \\
\hline Mendenhall [23] & $\left\{\begin{array}{l}1914 \\
1917\end{array}\right.$ & 1.44 & 1.439 \\
\hline Michel $[24] \ldots$ & 1022 & 1.427 & 1.427 \\
\hline \multicolumn{3}{|l|}{$\begin{array}{l}\text { Unweighted mean .. } \\
\text { Mean deviation..... }\end{array}$} & $\begin{array}{l}1.4361 \\
0.0059\end{array}$ \\
\hline
\end{tabular}

All the values listed in the third column except those of Coblentz and of Holborn and Valentiner represent separate determinations. Holborn and Valentiner's value of 1.435 is merely a correction by Valentiner of the value originally reported as 1.42. Coblentz's values of 1916 and 1922 represent only corrections of the value originally published in 1914.

It is evident that a mean of all the published values would have little or no significance. The best value derivable from these data would be a weighted mean of the selected values, but it is very difficult to assign weights to such observations. These selected values are the final values arrived at by the various groups of experimenters. In cases where reported values of $c_{2}$ were based on the equation $c_{2}=5 \lambda_{m} T$ obtained by using Wien's formula instead of eq 4 , the values have been recalculated.

\section{VALUES OF $c_{2}$ FROM $\sigma$}

The second method for obtaining $c_{2}$ is from measurements of $\sigma$ as defined by eq 3 and the relation given in eq 8 . Substitution of the numerical values of $c$ and $h$ from section III in the latter yields the relation

$$
c_{2}=0.12477 \sigma^{-1 / 4}
$$

In table 3 are listed the available data on $\sigma$ with values of $c_{2}$ calculated from eq 12 . 
TABLE 3.-Experimental values of $\sigma$ and corresponding values of $c_{2}$

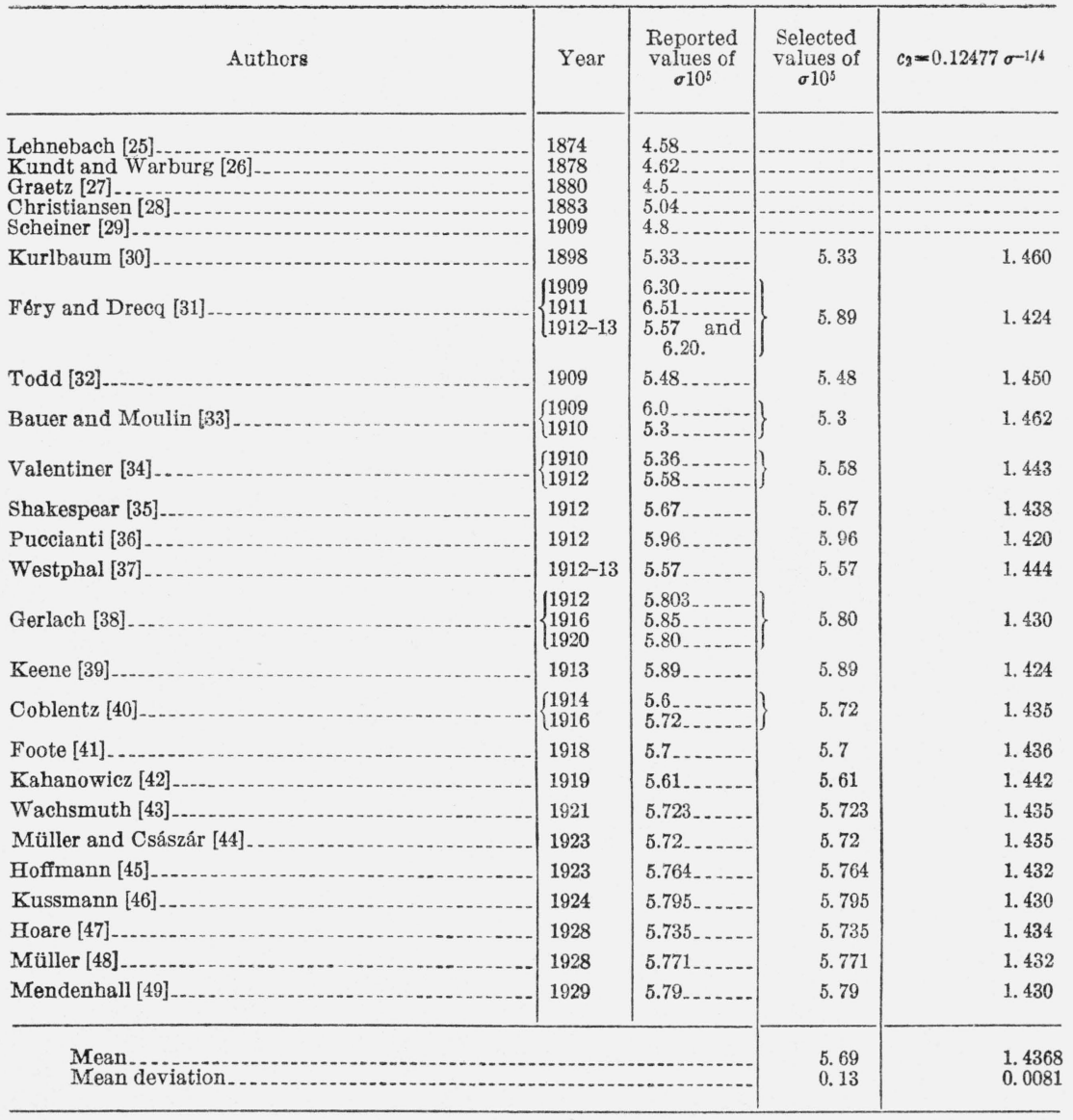

There is considerable uncertainty in these values arising from the corrections of about 2 percent which are usually made for the lack of blackness of the receiver. The values reported by Hoare and by Mendenhall are the only ones which do not involve any uncertainty from such corrections and are considered the most reliable. Many of the values originally reported have been corrected in later publications, but the original values are used except in cases where the corrections were made by the men who originally reported the results. Thus Valentiner corrected his value of 5.36 to 5.58 and Kurlbaum's value of 5.33 to 5.45. Valentiner's corrected and Kurlbaum's original values are selected for use in obtaining the mean. The first five values reported have been included in the table merely because of their historical interest.

A weighted mean of the values in table 3 would probably yield a better value than the one derived, but the assigning of such weights is not attempted. It is evident that in general the earlier values of $\sigma$ are smaller and the derived value of $c_{2}$ larger than the later ones. Thus the first 10 values of $c_{2}$ listed in table 3 have a mean of 1.439 , 
and the last 10 have a mean of 1.434. On the assumption that the later values are more reliable, they might be given more weight, but this assumption is open to some question. It is felt that there are enough values to minimize the effect of including a few which are believed to be somewhat less reliable than the others and the unweighted mean seems the wiser choice.

\section{VALUES OF $c_{2}$ BASED ON OPTICAL-PYROMETER MEASUREMENTS}

Another method which was used by Mendenhall [23] and by Day and Sosman [50] has not been given much attention because of the scarcity of the required experimental data. Equation 11, defining the International Temperature Scale of 1927 , may be written

$$
c_{2}=\lambda \ln \frac{J_{t}}{J_{\mathrm{Au}}} \frac{(t+273)\left(t_{\mathrm{Au}}+273\right)}{t-t_{\mathrm{uu}}}=\lambda \ln \frac{J_{t}}{J_{\mathrm{Au}}} f(t)
$$

The product $\lambda \ln J_{t} / J_{\mathrm{An}}$ may be measured with an optical pyrometer and $c_{2}$ calculated for any case where the corresponding temperatures are known on the thermodynamic scale.

Day and Sosman and Holborn and Day [51] have measured the temperature of a large number of fixed points on the constant-volume nitrogen gas scale with a pressure at $0^{\circ} \mathrm{C}$. of approximately $300 \mathrm{~mm}$ of mercury. The corrections to convert [52] these temperatures to the Centigrade Thermodynamic Scale are only a fraction of a degree even at the palladium point. Some of these temperatures, so corrected, are given in table 4. Day and Sosman did not make measurements at the copper-silver eutectic point, but their scale was so well described in terms of other fixed points, that temperatures in this region can be determined on their scale with considerable precision. Mendenhall and Forsythe [53] have determined the ratio of the temperatures of the gold and palladium points on the Kelvin Scale by means of eq 3 . They found that the energy radiated by a black body at the palladium point was 3.4626 times that radiated by a black body at the gold point. From this

$$
\frac{t+273}{1336}=\sqrt[4]{3.4626} \text {, or } t=1549.5^{\circ} \mathrm{C} .
$$

The value of $\lambda \ln J_{t} / J_{\text {Au }}$ for palladium listed in table 4 is that of Fairchild, Hoover, and Peters [54]. These authors compared their palladium with samples used by Day and Sosman and found the melting point to be the same within $0.1^{\circ} \mathrm{C}$. The value for the nickel point is that of Wensel and Roeser [55] and the remaining values represent unpublished work by these same experimenters.

In the case of copper, the size of the interval, about $20^{\circ} \mathrm{C}$, precludes the determination of $c_{2}$ to better than about 1 percent. Although Day and Sosman ascribe an uncertainty of about $3 /{ }^{\circ}$ to each of the gold and silver points, the nature of their measurements was such that the systematic or constant errors in their work would have the same sign and be of about the same magnitude at these two points. The difference between them is probably good to $\pm 0.2^{\circ} \mathrm{C}$, in the same 
way that the interval between gold and copper is certainly not in error by more than $0.2^{\circ}$. At the copper-silver eutectic point the uncertainty in $c_{2}$ is caused largely by the inability to make highly accurate optical-pyrometer measurements at the comparatively low brightness level corresponding to that temperature.

TABLE 4.-Values of $c_{2}$ based on optical pyrometry

\begin{tabular}{|c|c|c|c|c|c|c|}
\hline $\begin{array}{l}\text { Fixed } \\
\text { points }\end{array}$ & $\begin{array}{l}\text { Tempe- } \\
\text { rature }\end{array}$ & Authors & Method & $f(t)$ & $\left(\lambda \ln \frac{J_{t}}{J_{\mathrm{AU}}}\right) \times 10^{7}$ & $c_{8}$ \\
\hline $\begin{array}{l}\text { Pd....... } \\
\text { Ni....... } \\
\text { Cu...... } \\
\text { Aut..... }\end{array}$ & $\begin{array}{c}{ }^{\circ} C \\
1549.8 \\
1453.0 \\
1082.8 \\
1062.6\end{array}$ & \begin{tabular}{|} 
Day and Sosman \\
do do \\
do
\end{tabular} & $\begin{array}{l}\text { Gas thermometer.... } \\
\text { do do }\end{array}$ & $\begin{array}{r}4997 \\
5905 \\
896 \times 10^{2}\end{array}$ & $\begin{array}{c}2878 \\
2430 \\
159.5\end{array}$ & $\begin{array}{l}1.438 \\
1.435 \\
1.428\end{array}$ \\
\hline $\begin{array}{l}\mathrm{Ag} \\
\mathrm{Cu}-\mathrm{Ag}\end{array}$ & $\begin{array}{r}960.2 \\
778.2\end{array}$ & (Indirect) & do do & $\begin{array}{r}-16085 \\
-4937\end{array}$ & $\begin{array}{l}-891.5 \\
-1912\end{array}$ & $\begin{array}{l}1.434 \\
1.438\end{array}$ \\
\hline $\mathrm{Cu}$ & $\begin{array}{l}1084.3 \\
1064.2\end{array}$ & Holborn and Day. & . do do & $903 \times 10^{2}$ & 159.5 & 1. 441 \\
\hline $\mathrm{Ag}$ & 961.7 & -................................... & -....do do & -16108 & -891.5 & 1.436 \\
\hline $\mathrm{Pd}$ & $\begin{array}{l}1549.5 \\
1063.0\end{array}$ & $\begin{array}{l}\text { Mendenhall and For- } \\
\text { sythe. }\end{array}$ & $\begin{array}{l}\text { Radiation pyrometer-- } \\
\text { (Used as base).... }\end{array}$ & 5003 & 2878 & 1. 440 \\
\hline \multicolumn{6}{|c|}{$\begin{array}{l}\text { Unweighted mean } \\
\text { Mean deviation. }\end{array}$} & $\begin{array}{l}1.4364 \\
0.0029\end{array}$ \\
\hline
\end{tabular}

\section{VALUES OF $c_{2}$ FROM ATOMIC CONSTANTS}

In view of the material presented in the preceding sections, the adoption in 1927 of $c_{2}=1.432 \mathrm{~cm}$ deg in the definition of the International Temperature Scale seems to call for some explanation.

The values of $c_{2}$ derivable from experimental values of $\lambda_{m} T$ and from the gas-thermometer determination of the palladium point were essentially the same in 1927 as those given in this paper, namely, 1.436 and 1.438 , respectively. The value of $c_{2}$ derivable from $\sigma$, however, was about $1 / 4$ percent lower than that derived today from the same value of $\sigma$, because the accepted value of $h$ was then about 6.55 , or 1 percent, lower than that accepted today. A value of $h=6.55$ and $\sigma=5.7$ corresponds to a value of $c_{2}=1.432_{8}$. Moreover, the values of $h / e$ advocated in 1927 yielded values of 1.432 to 1.433 . As the confidence placed in the available values of $h$ and $h / e$ at that time was such that they were generally expressed to four or five significant figures, the discrepancies in $c_{2}$ were not considered serious. The data on $\lambda_{\mathrm{m}} T$ are not such as, in themselves, to inspire much confidence, and the value of $c_{2}$ deduced from the temperature of the palladium point was considered to indicate that Day and Sosman were overly optimistic in claiming an accuracy of $2^{\circ}$ for their determination of this temperature. The history of the values of $h$ and of $h / e$, as outlined in table 5 and figure 1, explains the choice of the value of $c_{2}$ (shown by the star at 1927 in fig. 1) used in defining the temperature scale. 


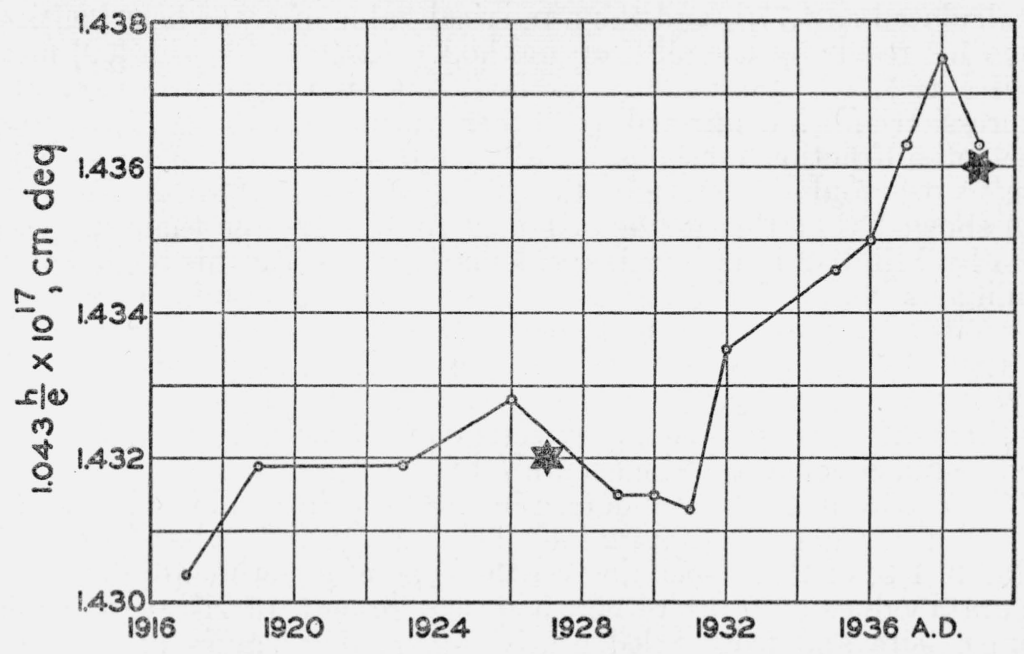

FIGURE 1.-Values of $c_{2}$ calculated from $\mathrm{h} / \mathrm{e}$.

TABLE 5.-Values of $h$ and of h/e which have been recommended by various reviewers

\begin{tabular}{|c|c|c|c|c|}
\hline Year & Recommended by & $h \times 10^{27}$ & $(h / e) \times 10^{17}$ & $1.0430(h / e) \times 10^{17}=c_{3}$ \\
\hline $\begin{array}{l}1917 \ldots \\
1919-\ldots \\
1923 \\
1926 \ldots \\
1927 \ldots \\
\end{array}$ & $\begin{array}{l}\text { Millikan [56] } \\
\text { Birge [57] } \\
\text { Int. Crit. Tables [58] } \\
\text { Birge [59] } \\
\text { ITS [1] }\end{array}$ & $\begin{array}{l}6.547 \\
6.550 \\
6.554 \\
6.560\end{array}$ & $\begin{array}{l}\text { 1. } 3714 \\
\text { 1. } 3729 \\
\text { 1. } 3729 \\
1.3737 \\
1.373\end{array}$ & $\begin{array}{l}1.4304 \\
1.4319 \\
1.4319 \\
1.4328 \\
1.432\end{array}$ \\
\hline $\begin{array}{l}1929 \\
1930 \\
1931 \\
1932 \\
1935\end{array}$ & $\begin{array}{l}\text { Birge [11] } \\
\text { Millikan [60] } \\
\text { Bond [61] } \\
\text { Birge [62] } \\
\text { Beardon [63] }\end{array}$ & $\begin{array}{l}\text { 6. } 547 \\
6.547 \\
6.5586 \\
6.5443 \\
6.558\end{array}$ & $\begin{array}{l}1.3725 \\
1.3725 \\
1.3723 \\
1.3744 \\
1.3755\end{array}$ & $\begin{array}{l}1.4315 \\
1.4315 \\
1.4313 \\
1.4335 \\
1.4346\end{array}$ \\
\hline $\begin{array}{l}1936 \ldots \\
1937 \ldots \\
1938 \ldots \\
1939 \ldots\end{array}$ & $\begin{array}{l}\text { Birge [64] } \\
\text { Von Friesen }[65] \\
\text { Millikan }[66] \\
\text { Dunnington }[67]\end{array}$ & $\begin{array}{l}6.58 \text { and } 6.61 \\
6.61 \\
6.61 \\
6.6133\end{array}$ & $\begin{array}{l}\text { 1. } 37588 \\
1.3771 \\
1.3782 \\
1.3771\end{array}$ & $\begin{array}{l}1.4350 \\
1.4363 \\
1.4375 \\
1.4363\end{array}$ \\
\hline
\end{tabular}

Since the values of $c, F$, and $R$ are all very accurately known, the quantity $c F / R=1.0430 \times 10^{17}$ may be taken as exact and eq 9 written as

$$
c_{2}=1.0430 h / e \times 10^{17} .
$$

The confidence which may be placed in this value of $c F / R$ is indicated by the fact that the constants in the oldest reference available in which all three are given, the 1897 edition of the Smithsonian Tables, yield 1.0429, those in the first (1910) volume of "Tables Annuelles de Constantes" yield 1.0428, while those recommended by Birge [11] in 1929 yield 1.0431. Using the constants in the ICT, the result is 1.0435 . The value of $c_{2}$ calculated from formula 14 therefore, will be as accurate as the value used for $h / e$.

The reason for the sharp upturn in the accepted values of $h$ and $h / e$ about 1932 is to be found in a change in the views held in regard to the electronic charge, $e$. Up to 1928 no determination had been made since Millikan [68] obtained the value $4.774 \times 10^{-10}$ (esu) (later [60] 
recalculated as 4.770) and the numerical value of $e$ was based entirely upon his result by the oil drop method. In 1928 Bäcklin [69] measured $e$ as 4.793 by an X-ray method, but his work made very little impression until confirmed by other workers both by X-ray and electron-diffraction methods. This led to a reexamination of Millikan's work, and a redetermination of the viscosity of air by Kellström [70] showed that this is about 1 part in 150 greater than the value used by Millikan in his original calculations. With this modification, Millikan's value is in agreement with values obtained by other methods as well as with a more recent [71] and accurate determination of 4.800 by the oil drop method. In the last 10 years there have appeared seven determinations [65] of $e$, ranging from 4.793 to 4.806, by three different methods, the average of which is $4.800 \times 10^{-10}$ (esu). This value is believed to be accurate to \pm 0.1 percent.

The constant $h$ is never determined except in combination with $e$, the quantity actually determined being $Q=h / e^{n+1}$, where $n$ has the value $0,1 / 3$, or $2 / 3$, depending on the type of experiment. The most accurate values of $Q$ are obtained in experiments of X-ray diffraction from calcite and from ruled grating s $^{3}$ yielding values of $h / e^{4 / 3}$ and $h / e^{5 / 3}$, respectively. We have then that

$$
\frac{d(h / e)}{h / e}=n \frac{d e}{e}+\frac{d Q}{Q}
$$

so that, aside from the error in $Q$, the percentage error in $h / e$ is always less than that in $e$. The various determinations of $h / e^{n+1}$ have been carefully examined and the values of $h / e$ shown in table 6 have been derived on the following basis:

$$
\begin{aligned}
\text { Calcite grating space } & =3.0356 \times 10^{-8}[72] \\
c & =2.99776 \times 10^{10} \\
e & =4.800 \times 10^{-10}
\end{aligned}
$$

\begin{tabular}{|c|c|c|c|}
\hline Authors & Year & Method & $(h / e) \times 10^{17}$ \\
\hline Lawrence [73] & 1926 & Ionization potentials & 1. 3753 \\
\hline $\begin{array}{l}\text { Millikan [74] } \\
\text { Lukirsky and Prilězaev [75] } \\
\text { Olpin [76] }\end{array}$ & $\begin{array}{l}1916 \\
1928 \\
1930\end{array}$ & \begin{tabular}{|l} 
Photoelectric effect..... \\
\end{tabular} & $\begin{array}{l}\text { 1. } 3777 \\
\text { 1. } 3711 \\
1.3748\end{array}$ \\
\hline $\begin{array}{l}\text { Wagner [77] } \\
\text { Duane, Palmer, and Yeh [78] } \\
\text { Feder [79] } \\
\text { Kirkpatrick and Ross [80] } \\
\text { Sehaitberger [81] }\end{array}$ & $\begin{array}{l}1920 \\
1921 \\
1930 \\
1934 \\
1935\end{array}$ & 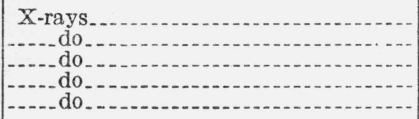 & $\begin{array}{l}1.3727 \\
1.3784 \\
1.3757 \\
1.3752 \\
1.3768\end{array}$ \\
\hline From Rydberg constant [82] $\ldots \ldots$ & 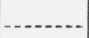 & $e / m=5.2730 \times 10^{17}$ & 1. 3787 \\
\hline $\begin{array}{l}\text { Gnan [83] } \\
\text { Von Friesen }[84]\end{array}$ & $\begin{array}{l}1934 \\
1935\end{array}$ & Electron diffraction . . & $\begin{array}{l}1.3765 \\
1.3769\end{array}$ \\
\hline Eddington [85] & 1933 & $\operatorname{ch} / 2 \pi e^{2}=137$ & 1.3783 \\
\hline
\end{tabular}

1 International Volt $=1.00034$ Absolute Volts

TABLE 6.-Experimental values of h/e

3 The latter method yields

$$
\frac{h}{e^{4 / 3} m^{1 / 3}}=\frac{h}{e^{5 / 3}}\left(\frac{e}{m}\right)^{1 / 3},
$$

but the value of $e / m$ is an independently determined constant, the measurement of which is not affected by $e$, and thus becomes part of the measurable quantity $Q$. In fact the measured value $e / m$, together with $e$, 
There are many determinations from ionization potentials but, in most of these, accuracy beyond two significant figures was not even sought. Lawrence's result is the only one worth considering here. Lawrence's reported value of 1.3737 from the ionization potential of mercury vapor and the equation

$$
V e=\frac{h c}{\lambda}, \text { or } \frac{h}{e}=\frac{V \lambda}{c}
$$

was based on the international volt and $c=3 \times 10^{10}$. On the basis used here we get

$$
h / e=1.00034 \times \frac{3}{2.99776} \times 1.3737=1.3753
$$

Strictly speaking, this is in no sense a "correction" of Lawrence's result, but an expression of $h / e$ on a different basis. Lawrence's actual result is a value of 10.40 international volts for the limit of the mercury absorption spectrum $\lambda=1.188 \times 10^{-5}$. From this we have that

$$
\frac{h}{e}=\frac{1.00034 \times 10.40 \times 10^{8}}{2.99776 \times 10^{10}} \times \frac{1.188 \times 10^{-5}}{2.99776 \times 10^{10}}=1.3753 \times 10^{-17}
$$

This result is entirely independent of the value of $e$.

From measurements of the photoelectric effect, Millikan obtained a value of $h=6.57 \times 10^{-27}$ based on $c=3 \times 10^{10}$ and $e=4.774 \times 10^{-10}$. On our basis, therefore, his work yields

$$
h / e=\frac{6.57}{4.774} \times \frac{3}{2.99776} \times 1.00034=1.3777 .
$$

Lukirsky and Prilězaev obtained $h=6.543$ based on $e=4.774$. This result requires adjustment for $e$ and for reduction to the absolute volt, but not for $c$. Olpin obtained $h=6.541$, using sodium treated with sulfur vapor, and states in his prefatory abstract "An almost identical value is obtained for untreated sodium." However, in the body of the paper his result for untreated sodium is given as $h=6.6$, with the observation that it is not as reliable as the value 6.541. Von Friesen [65] in his table IV quotes Olpin's result as $h=6.561$, which is the mean obtained by giving the value 6.6 one-half as much weight as the value 6.541. This seems to be as good a way as any to treat Olpin's result, and from it we get

$$
h / e=\frac{6.561}{4.774} \times 1.00034=1.3748 .
$$

Determinations of $h / e$ by this method likewise do not require a knowledge of $e$.

The X-ray method also determines $h / e$ from eq 15 , that is,

$$
\frac{h}{e}=\frac{v \lambda}{c}=\frac{V \lambda}{c^{2}} \times 10^{8}=\frac{2 d V^{1}(1.00034) \sin \theta \times 10^{8}}{c^{2}},
$$

where $v$ is in (esu) of potential difference, $V$ is in absolute volts, $V^{1}$ is in international volts, and $d$ is the grating space of calcite. The result does not depend on $e$ unless the value used for $d$ is made to $132431-39-2$ 
depend on $e$. In the past, $d$ has usually been calculated from the physical properties of calcite, using an equation in which $d$ is proportional to $\sqrt[3]{e}$. When $e$ was put equal to 4.770 or 4.774 a value of $d$ (about $3.028 \times 10^{-8}$ ) was obtained which required X-ray wavelengths found with crystal spectrometers to be multiplied by 1.00248 to make them agree with X-ray wavelengths measured with ruled gratings [72]. In other words, measurements by the two methods will agree if $d$ for calcite is taken as $1.0025 \times 3.028 \times 10^{-8}=3.0356 \times 10^{-8}$. If, on the other hand, we calculate $d$ on the basis of $e=4.800$, we get $d=3.028$ $(4.800 / 4.770)^{1 / 3}=3.0344$. We get about the same values of $h / e$, therefore, from the crystal X-ray work by using the multiplying factor $(4.800 / e)^{1 / 3}$ or by using Beardon's [72] value of $d=3.0356$, which is obtained by comparing ruled-grating measurements with crystal measurements of X-ray wavelengths. The latter method is more direct and will be used. The following values of $V^{1} \sin \theta$ are available for calcite.

Wagner
Duane, Palmer, and Yeh
Feder
Kirkpatrick and Ross

Putting $d=3.0356$ and the above values of $V^{1} \sin \theta$ into eq 16 , we get the corresponding values of $h / e$ listed in table 6 . Schaitberger, on the other hand, used a rock-salt crystal, taking $d=2.814$. $\mathrm{He}$ expressed his result as $h / e \alpha=1.3743$ on the basis of the absolute volt, $e=4.774$, and $c=2.99774$, where $\alpha$ is the factor which converts the conventional $d$ to true $d$. The simplest way to get $h / e$ from this is to put

$$
\alpha=\sqrt[3]{\frac{4.800}{4.774}}=1.0018,
$$

whence $h / e=1.3768$. Kirkpatrick and Ross have characterized Duane's result as too high and Wagner's as too low. They apply corrections to make the former 2034.6 but do not correct the latter. It seems advisable to take each result as reported, as it makes very little difference in the result sought here.

To get $h / e$ from the Rydberg number, $R_{\infty}$, we use the equation

$$
\frac{h}{e}=\sqrt[3]{\frac{2 \pi^{2} e^{2}}{R_{\infty} c e / m}}
$$

The value of $R_{\infty}$ is 109737.4 [11], and, on the basis of the selected values of $e$ and $c, h / e$ is simply a question of the numerical value of $e / m$. However, Birge [82] has recently published a review of 10 determinations of $e / m$ and concludes that the best derivable value is $1.7591 \times 10^{7}(\mathrm{emu}) \mathrm{g}^{-1}$, or $5.273 \times 10^{17}(\mathrm{esu}) \mathrm{g}^{-1}$, on a basis substantially equivalent to the one used in this paper. Dunnington [67] arrives at the value $1.7590 \times 10^{7}(\mathrm{emu}) \mathrm{g}^{-1}$. Inasmuch as the highest and the lowest of the 10 values listed by Birge yield values of $h / e$ differing by less 0.1 percent, it is evident that the value of $h / e$ from equation 17 is largely dependent on and not much more accurate than the value used for $e$. For this reason it should not be given as much weight as would be the case if a more accurate value of $e$ were available. 
Gnan reported $h / e$ as 1.374 , but points out that his result depends on the value of $e$. He then states that his explicit result is $h / e^{4 / 3}=$ $1.758 \times 10^{-14}$, which is independent of his crystal constant. From this, $h / e=\sqrt[3]{.4800} \times 1.758 \times 10^{-17}=1.3765 \times 10^{-17}$. Unfortunately, Von Friesen's Uppsala dissertation is not available to the writer, but Von Friesen [57] himself gives his result for $h$ as $6612 / 6610$ of that of Gnan. From this we obtain $h / e=1.3769$ for Von Friesen's work.

Eddington's theoretical value of $1 / 137$ for the fine structure constant is listed as a matter of interest. The mean obtained from the data listed in table 7, however, does not include this value, although, as a matter of fact, the mean is not appreciably changed if this value is included.

TABLE 7.-Summary of values of $h / e$, in erg sec $(e s u)^{-1}$ and the corresponding values of $c_{2}$ in $\mathrm{cm} \mathrm{deg}$

\begin{tabular}{|c|c|c|c|c|}
\hline Method & $\begin{array}{c}\text { Determi- } \\
\text { nations }\end{array}$ & $h / e \times 10^{17}$ & $c_{2}$ & Weight \\
\hline $\begin{array}{l}\text { Ionization potentials. } \\
\text { Photoelectric effect } \\
\text { X-rays } \\
\text { Rydberg number } \\
\text { Electron diffraction } \\
\text { Fine structure. }\end{array}$ & $\begin{array}{l}1 \\
3 \\
5 \\
? \\
2 \\
\end{array}$ & $\begin{array}{l}\text { 1. } 3753 \\
\text { 1. } 3745 \\
1.3758 \\
\text { 1. } 3787 \\
\text { 1. } 3767 \\
\text { (1. } 3783)\end{array}$ & $\begin{array}{l}1.4344 \\
1.4336 \\
1.4350 \\
1.4380 \\
1.4359 \\
(1.4376)\end{array}$ & $\begin{array}{l}1 \\
3 \\
5 \\
5 \\
2 \\
0\end{array}$ \\
\hline $\begin{array}{l}\text { Weighted mean } \\
\text { Mean deviation }\end{array}$ & & & $\begin{array}{r}1.4358 \mathrm{~cm} \mathrm{deg} \\
0.0014\end{array}$ & $\cdots$ \\
\hline
\end{tabular}

It might be pointed out that according to Bond [86], all experimental determinations of $e / m$ are in reality determinations of (136/137) $(e / m)$. On Bond's theory the value of $c_{2}$ from the Rydberg number is reduced by about $1 / 4$ percent, or, in this case, from 1.4380 to 1.4344 .

Perhaps it should also be mentioned that Anderson [87] on the basis of a pseudo-frictional effect between light quanta has deduced the relation

$$
\sigma=\left(\frac{\pi^{2}}{90}\right)^{1 / 3} \frac{2^{4} \pi^{11} c^{2} h}{3^{7} 5^{2} c_{2}^{4}}=1.01 \sigma \text { (from eq. } 10 \text { ) }
$$

This theory was apparently devised to explain discrepancies between experimental values of $\lambda_{m} T$ and $\sigma$ which have disappeared with the abandonment of the old value of $e$.

\section{SUMMARY}

All of the experimental data available have been used to derive values of $c_{2}$. This was merely a matter of choice, and the same data can be used in each case to calculate values of the other radiation constants. For example, the relation between $\lambda_{m} T$ and $c_{2}$ is exact. Similarly, the values of $\sigma$ and $c_{1}$ listed on page 392 have been calculated from $c_{2}$. The values of $c_{2}$ from various sources are summarized in table 8 , and the final mean value of $c_{2}$ there recorded will yield values of the other radiation constants which embody all the experimental data which have been considered. 
TABLE 8.-Summary of values of $c_{2}$ from all sources

\begin{tabular}{|c|c|c|}
\hline Source & $c_{2}$ in $\mathrm{cm} \mathrm{deg}$ & Weight \\
\hline $\begin{array}{l}\lambda_{m} T \\
\text { Optical pyrometry } \\
\text { Atomic constants }\end{array}$ & $\begin{array}{l}1.4361 \pm 0.0050 \\
1.4368 \pm .0040 \\
1.4364 \pm .0020 \\
1.4358 \pm .0015\end{array}$ & 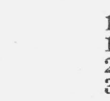 \\
\hline $\begin{array}{l}\text { Weighted mean } \\
\text { Mean deviation. }\end{array}$ & $\begin{array}{l}1.4362 \pm 0.001 \\
0.0003\end{array}$ & \\
\hline
\end{tabular}

It would seem that the probability is small that the true value of $c_{2}$ lies outside the limits $1.436 \pm 0.001 \mathrm{~cm} \mathrm{deg.} \mathrm{The} \mathrm{values} \mathrm{of} \mathrm{a}$ set of mutually consistent constants derived from all available data are listed below.

$$
\begin{aligned}
& c_{1}=(3.732 \pm 0.006) \times 10^{-5} \mathrm{erg} \mathrm{cm}^{2} \mathrm{sec}^{-1} \\
& c_{2}=1.436 \pm 0.001 \mathrm{~cm} \mathrm{deg} \\
& \lambda_{m} T=(2892 \pm 2) \times 10^{-4} \mathrm{~cm} \mathrm{deg} \\
& \nu_{m} / T=(5890 \pm 4) \times 10^{7} \mathrm{deg}^{-1} \mathrm{sec}^{-1} \\
& \sigma=(5.70 \pm 0.02) \times 10^{-5} \mathrm{erg} \mathrm{sec}^{-1} \mathrm{~cm}^{-2} \mathrm{deg}^{-4} \\
& c=(2.9978 \pm 0.0002) \times 10^{10} \mathrm{~cm} \mathrm{sec}^{-1} \\
& F=(2.8926 \pm 0.0003) \times 10^{14}(\mathrm{esu}) \mathrm{mole}^{-1} \\
& T_{0}=273.16 \pm 0.02 \mathrm{deg} \\
& R=(8.3142 \pm 0.0010) \times 10^{7} \mathrm{erg} \mathrm{deg}^{-1} \mathrm{~mole}^{-1} \\
& k=(1.378 \pm 0.002) \times 10^{-16} \mathrm{erg} \mathrm{deg}^{-1} \\
& e=(4.800 \pm 0.004) \times 10^{-10}(\mathrm{esu}) \\
& p=1.00048 \\
& q=0.99986 \\
& p q=1.00034 \\
& \bar{h}=(6.61 \pm 0.01) \times 10^{-27} \text { erg sec } \\
& h / e=\left(1.377^{ \pm} \pm 0.001\right) \times 10^{-17} \mathrm{erg} \mathrm{sec}(\mathrm{esu})^{-1} \\
& e / m=(5.273 \pm 0.002) \times 10^{17}(\mathrm{esu}) g^{-1} \\
& M=\text { Least mechanical equivalent of light }=(151 \pm 1) \times 10^{-5} \text { watt } \\
& \text { ("new" lumen) })^{-1} \text {. }
\end{aligned}
$$

Fine-structure constant (reciprocal $=137.0 \pm 0.2$ ).

The writer has attempted to handle the data in such a manner as to secure results which reflected his own personal opinions as little as possible. An attempt has been made to avoid criticism by refusing to assign weights to published results or to apply corrections not pointed out by those who reported the original results. The practice of weighting values by different observers in the inverse ratio of the uncertainties which the observers attach to their own results seems a very questionable one.

In conclusion, it may be of interest to say something about the least mechanical equivalent of light, $M$. This is not a constant in the ordinary sense because it is not fixed by the units of length, mass, time, and luminous intensity but involves, in addition, the physiological and psychological characteristics which are arbitrarily assigned to some hypothetical individual designated as standard, that is, the so-called "ICI standard observer." In the past a determination of $M$ has been merely a matter of determining the luminous intensity of a black body at some measured temperature and then calculating 
$M$ on the basis of $c_{2}, \sigma$ or $c_{1}$, and the selected standard observer. In terms of the present "International" candle, $1 \mathrm{~cm}^{2}$ of a black body at the freezing point of pure platinum emits $58.9 \pi$, or $185.0 \pm 0.2$ international lumens [88]. The freezing temperature of platinum is 1773.5 on the international scale $\left(c_{2}=1.432\right)$. On January 1,1940 , a new system of photometric units is scheduled to go into effect. The numerical value of $M$, in terms of the "new" units, will increase by approximately 2 percent, because on that date the luminous emission from $1 \mathrm{~cm}^{2}$ of a black body at the freezing point of pure platinum becomes $60 \pi$ "new" lumens by definition. $M$, thereupon, becomes fixed by $c_{2}, \sigma$, and the standard observer (luminosity factors). On the basis of $c_{1}=3.732 \times 10^{-5}$ and $c_{2}=1.436$, we have that the freezing point of platinum is $2043.8^{\circ} \mathrm{K}$ and that $c_{2} / 2043.8=7.0261 \times$ $10^{-4}$, so that

$$
M=A \int_{0}^{\infty} L_{\lambda} \lambda^{-5}\left(e^{\frac{7.0261}{\lambda \times 10^{4}}}-1\right)^{-1} d \lambda,
$$

where the values of $L_{\lambda}$ are the internationally accepted [80] luminosity factors describing the ICI standard observer and $A=c_{1} / 60 \pi=$ $1.980 \times 10^{-7} \mathrm{erg} \mathrm{sec}^{-1} \mathrm{~cm}^{2}$ ("new" lumen) $)^{-1}$. From this relation $M$ is found to be $1.508 \times 10^{4}$ ergs per "new" lumen second, or 0.001508 watt per "new" lumen. On the basis of $c_{2}=1.432, M=0.00157$ watt per "new" lumen, which is identical with the former value of $M=$ 0.00160 watt per "international" lumen.

\section{REFERENCES}

[1] George K. Burgess, BS J. Research 1, 635 (1928) RP22.

[2] Wm. F. Roeser, BS J. Research 3, 343 (1929) RP99.

[3] Roeser and Dahl, BS J. Research 10, 661 (1933) RP557.

[4] Karolus and Mittelstaedt, Physik. Z. 29, 698 (1928).

[5] Pease and Pearson, Astrophys. J. 82, 26 (1935).

[6] Heuse and Otto, Ann. Physik [5] 4, 778 (1930).

[7] Keesom and Tuyn, Comm. Leiden, Supp. 78, 1 (1936).

[8] J. R. Roebuck, Phys. Rev. [2] 50, 370 (1936).

[9] Kinoshita and Oishi, Phil. Mag. [7] 24, 52 (1937).

[10] J. R. Beattie, private communication, Feb. 20, 1939.

[11] R. T. Birge, Rev. Mod. Phys. 1, 1 (1929).

[12] Curtis, Curtis, and Critchfield, J. Research NBS 22, 485 (1939) RP1200.

[13] R. T. Birge, Phys. Rev. [2] 54, 972 (1938).

[14] Rosa and Vinal, Proc. Nat. Acad. Sci. 3, 59 (1917).

[15] G. W. Vinal, Cong. Int. Elec. Paris, 2 Sec. Rap. 6 (1932); Vinal and Bates, Bul. BS 10, 425 (1914) S218.

[16] Report to the Int. Com. on Elec. Units and Stds., Misc. Pub. BS, M16, 67 (1912).

[17] S. von Friesen, Proc. Roy. Soc. (London) [A] 160, 424 (1937).

[18] Lummer and Pringsheim, Verhandl. deut. Phys. Ges. 1, 23 and 215 (1899); Ann. Physik [4] 3, 159 (1900); Verhandl. deut. Phys. Ges. 3, 36 (1901).

[19] F. Paschen, Sitzber. kgl. Akad. Wiss. 1899, 405 and 959 (1899); Ann. Physik [4] 4, 277 (1901); H. Wanner, Ann. Physik [4] 2, 141 (1900); Paschen and Wanner, Sitzber. kgl. Akad. Wiss. 1899, 5 (1899).

[20] Holborn and Valentiner, Ann. Physik [4] 22, 1 (1907); S. Valentiner; Ann. Physik [4] 39, 489 (1912).

[21] E. Warburg, Sitzber. kgl. Akad. Wiss. $1910_{2}, 925$ (1910); Warburg and Leithauser, Z. Instrumentenk. 30, 118 (1910); 31, 124 (1911); Warburg, Hupka, and Müller, Z. Instrumentenk. 32, 134 (1912); Warburg, Leithauser, Hupka, and Müller, Ann. Physik [4] 40, 609 (1913); Sitzber. kgl. Akad. Wiss. 1913 1,35 (1913); Warburg and Müller, Ann. Physik [4] 48, 410 (1915); Z. Instrumentenk. 35, 98 (1915).

[22] W. W. Coblentz, Bul. BS 10, 1 (1914) S204; 13, 459 (1917) S284; 17, 7 (1922) S406. 
[23] C. E. Mendenhall, Phys. Rev. [2] 10, 515 (1917); Mendenhall and Forsythe, Phys. Rev. [2] 4, 62 (1914).

[24] G. Michel, Z. Physik \$, 285 (1922).

[25] A. Lehnebach, Pogg. Ann. 151, 96 (1874).

[26] Kundt and Warburg, Pogg. Ann. 156, 207 (1878).

[27] L. Graetz, Ann. Physik [3] 11, 913 and 930 (1880).

[28] C. Christiansen, Ann. Physik [3] 19, 267 (1883).

[29] J. Scheiner, Pub. Ast. Obs. Potsdam 17, 267 (1909).

[30] F. Kurlbaum, Ann. Physik [3] 65, 746 (1898).

[31] Ch. Féry Compt. rend. 148, 515 (1909); Féry and Drecq, Compt. rend. 152, 590 (1912); J. phys. [V] 1, 551 (1911); Compt. rend. 155, 1239 (1912); J. phys. [V] 3, 380 (1913).

[32] G. W. Todd, Proc. Roy. Soc. (London) [A] 83, 19 (1909).

[33] Bauer and Moulin, Compt. rend. 149, 988 (1909); Compt. rend. 150, 167 (1910); J. phys. 9, 468 (1910).

[34] S. Valentiner, Ann. Physik [4] 31, 275 (1910); Ann. Physik [4] 39, 489 (1912).

[35] G. A. Shakespear, Proc. Roy. Soc. (London) [A] 86, 180 (1912).

[36] L. Puccianti, Nuovo cimento [6] 4, 31 (1912).

[37] W. H. Westphal, Verhandl. deut. Phys. Ges. 14, 987 (1912); 15, 897 (1913).

[38] W. Gerlach, Ann. Physik [4] 38, 1 (1912); [4] 50, 259 (1916); Z. Physik 2, $79(1920)$.

[39] H. B. Keene, Proc. Roy. Soc. (London) [A] 88, 49 (1913).

[40] W. W. Coblentz, Physik. Z. 15, 762 (1914); Bul. BS 12, 553 (1916) S262.

[41] P. D. Foote, Bul. BS 14, 605 (1918) S323.

[42] M. Kahanowicz, Rend. accad. Lincei [5] 28, 73 (1919).

[43] R. Wachsmuth, Verhandl. deut. Physik. Ges. [3] 2, 36 (1921).

[44] Müller and Császár, Z. Instrúmentenk. 44, 118 (1923).

[45] K. Hoffmann, Z. Physik 14, 301 (1923).

[46] A. Kussmann, Z. Physik 15, 58 (1924).

[47] F. E. Hoare, Phil. Mag. [7] 6, 828 (1928).

[48] C. Müller, Wien-Harms HB IX [1] 447 (1929).

[49] C. E. Mendenhall, Phys. Rev. [2] 34, 502 (1929).

[50] Glazebrook's Dictionary of Applied Physics, 1, 863 (1922); Carnegie Inst. Wash. Pub. No. 456.

[51] Day and Sosman, Carnegie Inst. Wash. Pub. 157 (1911); Holborn and Day, Am. J. Sci. [4] 10, 171 (1900).

[52] E. Buckingham, Bul. BS 3, 237 (1907) S57.

[53] Mendenhall and Forsythe, Phys. Rev. [2] 4, 62 (1914).

[54] Fairchild, Hoover, and Peters, BS J. Research 2, 931 (1929) RP65.

[55] Wensel and Roeser, BS J. Research 5, 1309 (1930) RP258.

[56] R. A. Millikan, Phil. Mag. [7] 34, 1 (1917).

[57] R. T. Birge, Phys. Rev. [2] 14, 361 (1919).

[58] Pamphlet issued to cooperating in 1923.

[59] R. T. Birge, Science, 64, 180 (1926).

[60] R. A. Millikan, Phys. Rev. [2] 35, 1231 (1930).

[61] W. N. Bond, Phil. Mag. [7] 12, 632 (1931).

[62] R. T. Birge, Phys. Rev. [2] 40, 228 (1932).

[63] J. A. Beardon, Phys. Rev. [2] 48, 385 (1935).

[64] R. T. Birge, Nature, 13\%, 187 (1936).

[65] S. von Friesen, Proc. Roy. Soc. (London) [A] 160, 424 (1937).

[66] R. A. Millikan, Ann. Physik [5] 32, 34 (1938).

[67] F. G. Dunnington, Bul. Am. Phys. Soc. 14, Abst. 56 (Feb. 8, 1939).

[68] R. A. Millikan, Phys. Rev. [2] 2, 109 (1913).

[69] E. Bäcklin, Upps. Univ. Arsskr. (1928).

[70] G. Kellström, Phil. Mag. [7] 23, 313 (1937).

[71] Bäcklin and Flemberg, Nature, 13\%, 635 (1936).

[72] J. A. Beardon, Phys. Rev. [2] 48, 385 (1935).

[73] E. O. Lawrence, Phys. Rev. [2] 28, 947 (1926).

[74] R. A. Millikan, Phys. Rev. [2] 7, 355 (1916).

[75] Lukirsky and Prilězaev, Z. Physik 49, 236 (1928).

[76] A. R. Olpin, Phys. Rev. [2] 36, 251 (1930).

[77] E. Wagner, Physik. Z. 21, 621 (1920).

[78] Duane, Palmer, and Yeh, J. Opt. Soc. Am. 5, 376 (1924).

[79] H. Feder, Ann. Physik [5] 1, 497 (1929).

[80] Kirkpatrick and Ross, Phys. Rev. [2] 45, 454 (1y34).

[81] G. Schaitberger, Ann. Physik [5] 24, 84 (1935).

[82] R. T. Birge, Phys. Rev. [2] 54, 972 (1938). 
[83] J. Gnan, Ann. Physik [5] 20, 361 (1934).

[84] S. von Friesen, Upps. Univ. Arsskr. (1935).

[85] A. S. Eddington, Proc. Roy. Soc. (London) [A] 143, 327 (1933).

[86] W. N. Bond, Nature 135, 825 (1935).

[87] W. Anderson, Z. Physik 59, 700 (1930).

[88] Wensel, Roeser, Barbrow, and Caldwell, BS J. Research 6, 1103 (1931), RP325; G. Ribaud, Rev. d'Opt., 12, 289 (1933); Nat. Phys. Lab. Rep. p. 80 (1935).

[89] Proc. Int. Comm. Illum., 6th meeting, Geneva, p. 67 and 232 (1924).

Washington, December 15, 1938. 